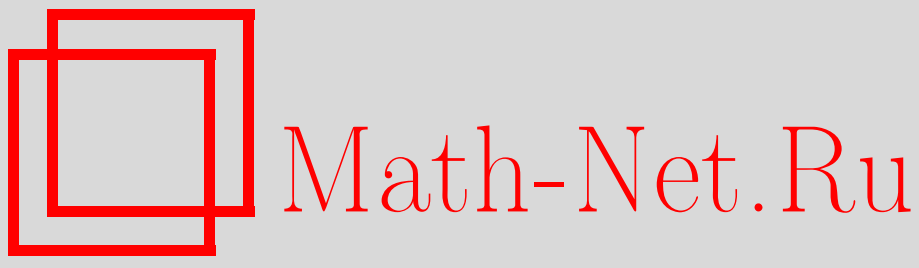

С. А. Шамрай, С. Л. Степанов, О пересчете кривых нагружения с ниспадающей ветвью в диаграмме $\sigma-\varepsilon$, Вестн. Сам. гос. техн. ун-та. Сер. Физ.-мат. науки, 2006, выпуск 43, 185-186

DOI: https://doi.org/10.14498/vsgtu474

Использование Общероссийского математического портала Math-Net.Ru подразумевает, что вы прочитали и согласны с пользовательским соглашением

http://www. mathnet.ru/rus/agreement

Параметры загрузки:

IP : 54.224 .187 .69

26 апреля 2023 г., 16:34:37

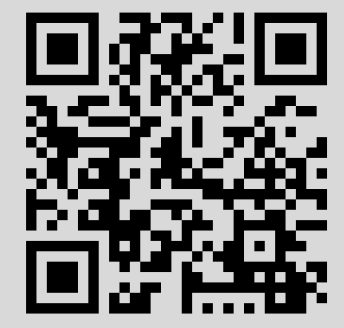




\section{О ПЕРЕСЧЕТЕ КРИВЫХ НАГРУЖЕНИЯ С НИСПАДАЮЩЕЙ ВЕТВЬЮ В ДИАГРАММЕ $\sigma-\varepsilon$}

Проведен анализ графика кривой упрочнения с ниспадающей ветвью. Показан алгоритм пересчета кривой упрочнения с учетом частичного разрушения материала.

В справочной литературе при описании механических характеристик конструкционных материалов часто встречается графики кривых упрочнения с ниспадающей ветвью диаграммы $\sigma-\varepsilon$, что соответствует разупрочнению материала (или его частичного разрушения). Ниже предлагается подход к пересчету кривых упрочнения с учетом частичного разрушения материала, основанный на работах [1-2].

Пусть в результате экспериментальных исследований получена диаграмма $\sigma-\varepsilon$ (рис.1.a).
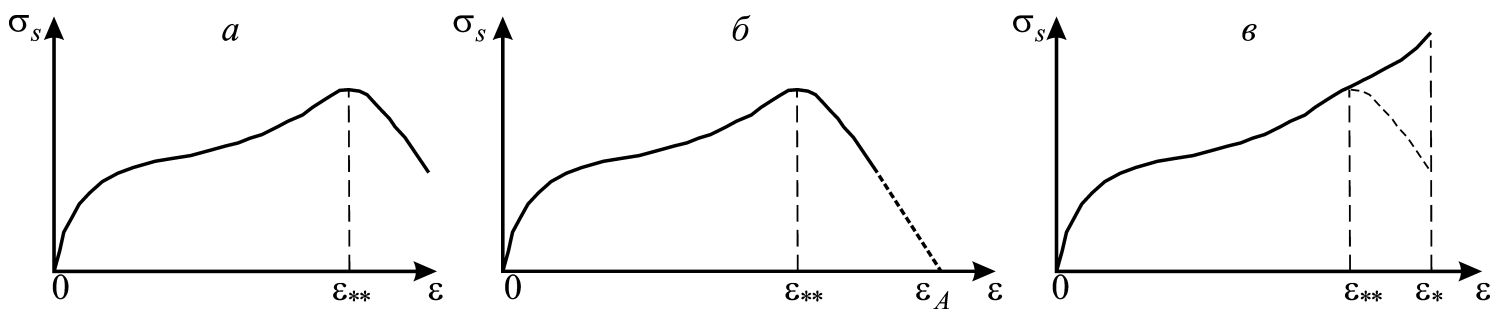

Р и с. 1 . Кривая упрочнения: $a-$ ниспадающая ветвь; $\sigma$ - ниспадающая ветвь, продолженная аппроксимацией; в - кривая упрочнения при пересчете с учетом трещины

Будем предполагать следующую модель поведения образца (плоский образец шириной $2 r$, толщиной -1 , рис. 2): а) на первом этапе при $\varepsilon \in\left[0 ; \varepsilon_{* *}\right]$ материал полосы деформируется однородно; б) в конце первого этапа внутри образца образуется макротрещина и однородное деформирование образца становится невозможным, поэтому при $\varepsilon \in\left[\varepsilon_{* *} ; \varepsilon\right]$ материал полосы деформируется неоднородно вдоль изолированных линий скольжения. При этом разупрочнение материала объясняется уменьшением эффективной площади поперечного сечения образца.

Алгоритм пересчета. Пусть дан график ниспадающей ветви (рис. 3). Продолжим линию аппроксимацией по параболе (рис. 4 и рис. 1,6$)$, тогда, определяя по графику $\varepsilon_{A}$ и $\varepsilon_{* *}$ и предполагая, что нам известно $l_{*}$, из формулы $\varepsilon=\ln \frac{l}{l_{0}}=\ln \left(\frac{1}{1-\psi}\right)$ получаем недостающие характеристики: $l_{0}=l_{*} \cdot \exp \left(-\varepsilon_{A}\right)$, $\psi_{*}=1-\exp \left(-\varepsilon_{A}\right), \quad \delta_{*}=\frac{l_{*}-l_{0}}{l_{0}} 100 \%, \quad l_{* *}=l_{0} \times$ $\times \exp \left(\varepsilon_{* *}\right), \psi_{* *}=1-\exp \left(-\varepsilon_{* *}\right), \delta_{* *}=\frac{l_{* *}-l_{0}}{l_{0}}$.
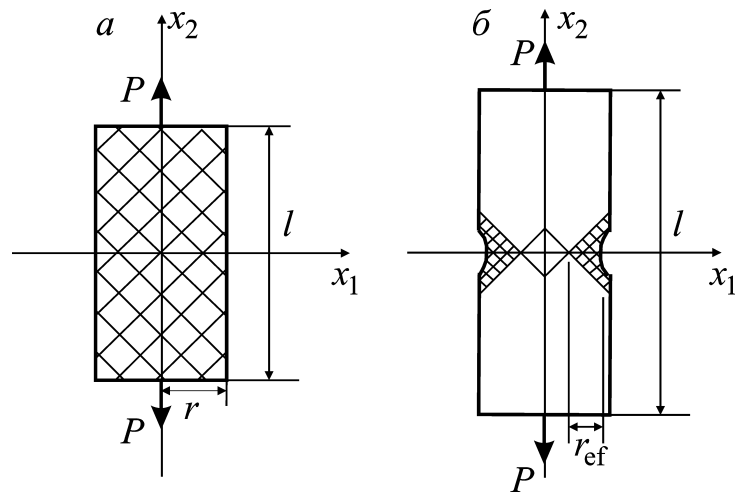

Р и с. 2. Деформирование материала

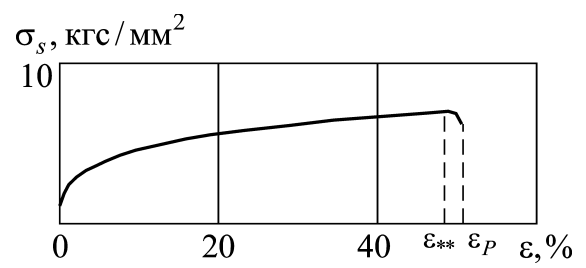

Р и с. 3. Кривые упрочнения при растяжении отожженного алюминия с диаметром зерна $d_{3}=150$ мкм; $(+22){ }^{\circ} \mathrm{C}$

(Kriol Hugo, Macherauch Eckard)

Предположим, что $l_{0}=5,65 \cdot \sqrt{F_{0}}$ (ГОСТ 1497-84. Металлы. Методы испытания на растяжение. Пункт 1.8.). Тогда $r_{0}=\frac{l_{0}^{2}}{2 \cdot 5,65^{2}}$. Из соотношения $l_{* * *} \cdot r_{* *}=l_{0} \cdot r_{0}$ имеем $r_{* *}=\frac{l_{0} \cdot r_{0}}{l_{* *}}$.Далее по формулам, приведенным в монографии [1] (§ 2.7. Определение констант разрушения на основе 


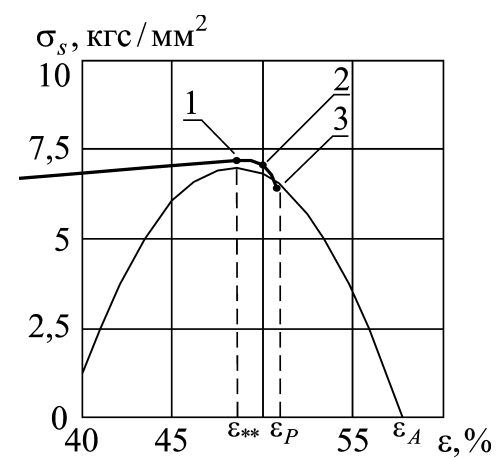

Р и с. 4. Ниспадающая ветвь, продолженная аппроксимацией

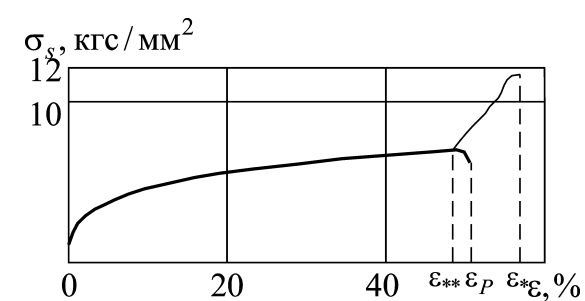

Р и с. 5. Кривые упрочнения при растяжении отожженного алюминия с диаметром зерна $d_{3}=150$ мкм или температуре $+22^{\circ} \mathrm{C}$ с учетом частичного разрушения материала

испытаний плоских образцов), определяем пластические константы разрушения $E_{* *}, E_{*}$, $W_{\text {冰, }}, W_{*}$.

На отрезке времени, когда $l \in\left[l_{* *} ; l_{*}\right]$, появляется еще одна эффективная характеристика: ширина $r_{\mathrm{ef}}=r-r_{\mathrm{tr}}$, где $r$ - текущая половина ширины пластины; $r_{\mathrm{tr}}-$ половина ширины трещины. При $l=l_{* *}$ имеем $r_{\mathrm{ef}}=r_{* *}=r$, а при $l=l_{*}-r_{\mathrm{ef}}=0$.

Соответственно эффективная площадь поперечного сечения пластины принимает значение: $F_{\text {ef }}=1 \cdot 2 \cdot r_{\text {ef }}=1 \cdot 2 \cdot\left(r-r_{\text {tr }}\right)$.

Сделаем перерасчет кривой упрочнения относительно эффективной площади: так как $F_{\text {ef }} \rightarrow 0$, а напряжение течения вычисляется по формуле $\sigma_{s}=\frac{P}{F_{\text {ef }}}$, то при данном деформирующем усилии $P$ напряжение течения $\sigma_{s}$ будет не уменьшаться, а увеличиваться.

Соответственно получаем график представленный на рис. 5 (или рис. 1,8 ).

\section{БИБЛИОГРАФИЧЕСКИЙ СПИСОК}

1. Хромов А. И., Козлова О. В. Разрушение жесткопластических тел. Константы разрушения. - Владивосток: Дальнаука, 2005. - $159 \mathrm{c}$.

2. Пластические константы разрушения: Учеб. пособие / О. В. Козлова, А. П. Наумкин, А. И. Хромов, С. А. Шамpaй. - Комсомольск-на-Амуре: КнАГТУ, 2005. - 52 с.

Поступила 5.07.2006 2.

УдК 539.3

\section{С. Л. Степанов}

\section{ИССЛЕДОВАНИЕ СХОДИМОСТИ РЕШЕНИЯ УРАВНЕНИЙ ФРЕДГОЛЬМА В УПРУГОПЛАСТИЧЕСКИХ ЗАДАЧАХ МЕХАНИКИ РАЗРУШЕНИЯ}

Рассматриваются вопросы разрешимости и сходимости решения неоднородных уравнений Фредгольма второго рода с логарифмическим ядром, возникающих в задачах механики разрущения при моделировании пластических эффектов у вершин трещин с использованием подходов теории жесткопластического тела.

Для плоского напряженного состояния известно модельное представление пластических областей у вершин трещины как узких, вытянутых вдоль линии трещины зон, в которых действуют постоянные напряжения, равные пределу текучести $p(x)=\sigma_{s}$. Такое модельное представление называется моделью Леонова-Панасюка-Дагдейла или КРТ-моделью (КРТ - критическое раскрытие трещины). Использование в задачах механики разрушения для сквозных и несквозных трещин (царапин) некоторых решений теории жесткопластического тела приводит к граничным условиям, в которых в пластических зонах и на контуре трещины вместо известного распределения напряжений $p(x)=\sigma(x)$ задается связь между напряжениями в пластических зонах и на берегах трещины и смещениями этих берегов в виде: 